\title{
Peace Journalism not Alive? \\ (menganalisis peran media terhadap pemberitaan peace journalism pada konflik PT. Freeport di Papua)
}

\author{
Hariya Toni, Intan Kurnia Syaputri \\ Institu Agama Islam Negeri (IAIN) Curup \\ hariyatoni@iaincurup.ac.id, Intankurniasy@,iaincurup.ac.id
}

\begin{abstract}
The media has the potential to play a decisive role in helping peace conflict and conflict resolution or foster tension in the conflict. This paper tells the story of how the role of media in conflict, especially integrating the practice of peace journalism in conflict PT. Freeport in Papua, peace journalism whether it has been implemented or is the news that there is even lead to war journalism. The discussion in this paper starts from reviewing the concept of conflict, meaning peace and peace journalism, the media discourse on peace and conflict resolution and transformation of media. From the analysis has been done, we can conclude some online media have not been able to realize peace journlism or create a peaceful conflict reporting. News involving conflict PT. Freeport in Papua, the media tends to bring its role as an intensifier issue. Framing and agenda setting that created media tend to be oriented towards violence. This indicates that peace journalism is not yet living in conflict reporting. Media can not be freed from the presentation of news always involves a conflict there are those who 'win' and 'lose' because basically the media attempt to "sell" the news of the conflict.
\end{abstract}

Keywords: Media, Peace Journalism, Conflict, PT. Freeport

\begin{abstract}
Abstrak
Media memiliki potensi untuk memainkan peran dalammembantu menentukan perdamaian konflik dan resolusi konflik atau membina ketegangan dalam konflik. Paper ini bercerita tentang bagaimana peran media dalam konflik, khusunya mengintegrasikan praktik peace journalism pada konflik PT. Freeport di Papua, apakah peace journalism itu sudah diterapkan ataukah pemberitaan yang ada malah mengarah kepada war journalism. Pembahasan pada paper ini dimulai dari mengkaji konsep konflik, makna perdamaian dan peace journalism, wacana media tentang perdamaian serta resolusi konflik dan tranformasi media. Dari analisis yang telah dilakukan, dapat ditarik kesimpulan beberapa media online belum dapat mewujudkan peace journlism atau membuat pemberitaan konflik yang damai. Pemberitaan yang menyangkut konflik PT. Freeport di Papua media cenderung membawa perannya sebagai issue intensifier. Framing dan agenda setting yang
\end{abstract}

Jurnal Dakwah dan Komunikasi
IAIN Curup | E-ISSN 2548-3366 ; P- ISSN 2548-3293 
dibuat media cenderung berorientasi kepada kekerasan, hal ini mengindikasikan bahwa peace journalism belumlah hidup dalam pemberitaan konflik. Media tidak bisa terbebas dari penyajian pemberitaan konflik yang selalu melibatkan ada pihak yang 'menang' dan 'kalah' karena pada dasarnya media berupaya untuk "menjual" pemberitaan konflik tersebut.

Kata Kunci: Media, Peace Journalism, Konflik, PT. Freeport

\section{Pendahuluan}

Selama beberapa dekade terakhir, dunia diramaikan dengan terjadinya konflik-konflik yang tak terhitung diberbagai dimensi, untuk menyelesaikan konflik memerlukan upaya bersama. Pemahaman peran berbagai aktor dalam konflik sangat dibutuhkan. Dalam hal ini selain pemerintah nasional, organisasiorganisasi non pemerintah, media dan journalis juga memainkan peran penting. Mengingat jurnalis sebagai pembuat informasi, media berfungsi sebagai penyebaran informasi, membentuk persepsi dan menetapkan pembingkaian informasi serta memainkan peran dalam membentuk opini publik. Penyebaran informasi yang dilakukan media bisa membantu menentukan perilaku struktur sosial dan politik. ${ }^{1}$

Media dengan demikian memainkan peran dalam memfasilitasi pembangunan ruang publik dan politik demokrasi, dengan demikian kualitas informasi yang disebarkan menjadi perhatian utama. Frame berita menentukan apa yang dipilih, apa yang dikecualikan "tidak terlalu diekspose" dan apa yang ditekankan. Media memiliki potensi untuk memainkan peran yang menentukan dalam membantu perdamaian konflik dan resolusi konflik atau membina ketegangan dalam konflik atau bertindak sebagai agen destruktif dalam proses penyelesaian konflik. ${ }^{2}$ Perlu digaris bawahi, dalam hal ini bisa dikatakan peran jurnalis tidak akan bisa dipisahkan dengan peran media dalam pemberitaan konflik, profesionalisme jurnalis dan kepiawaian jurnalis dalam memberitakan dan mengkemas informasi sangat penting dalam pemberitaan konflik.

Balik berbicara mengenai media, dari perspektif yang lebil luas, peran penting media adalah membentuk keamanan dan perdamaian, perspektif ini menjadi eksplisit dalam konteks perubahan tren dalam skenario keamanan. Secara tradisional, "keamanan" dilihat semata-mata dari perspektif negara dan aparat militer, bagaimana cara-cara militer untuk mencapai suatu keamanan dan perdamaian. ${ }^{3}$ Namun, tumbuh sebuah realitas bahwa keamanan harus dilihat dari perspektif sosial yang lebih besar. Dalam pandangan perspektif ini, muncul

${ }^{1}$ Lynch, Jake \& Annabel McGoldrick.Responses to Peace Journalismhttp://jou.sagepub.com.ezproxy.ugm.ac.id/content/14/8/1041.full.pdf +html. diunduh tanggal 18 Juni 2016

${ }^{2}$ Ibid.

${ }^{3}$ Robby Aditya Putra. Dampak Film Para Pencari Tuhan Jilid X Terhadap Religiusitas Remaja. Jurnal Dakwah dan Komunikasi, v. 3, n. 1, p. 1-24, july 2018. 
pemahaman bahwa keamanan tidak bisa lagi dilihat dari sudut pandang tradisional negara dan militer, cara dimana media terlibat dengan masalah keamanan atau membentuk persepsi keamanan memiliki dampak yang mendalam bagi negara dan masyarakat. ${ }^{4}$

Dalam konteks ini pemahaman tentang peran media dalam situasi konflik dan meresolusi konflik sangat penting.Perkembangan teknologi selama beberapa tahun terakhir memastikan bahwa media merupakan arus utama dalam memainkan peran membentuk persepsi dan kebijakan yang berkaitan dengan konflik.

Faktanya,media (online/konvensional) telah muncul untuk menjadi arena pusat konflik. Penulis ingin membahas bagaimana peran media dalam konflik, khusunya mengintegrasikan praktik peace journalism pada konflik PT. Freeport di Papua, apakah peace journalism itu sudah diterapkan ataukah pemberitaan yang ada malah mengarah kepada war journalism. Untuk memulai pembahasan mengenai konflik ini, ada baiknya penulis menjelaskan terlebih dahulu bagaimana mapping pembahasan yang akan ditulis pada paper ini, yaitu dimulai dari mengkaji konsep konflik, makna perdamaian dan peace journalism, wacana media tentang perdamaian serta resolusi konflik dan tranformasi media. Selanjutnya, penulis menggambil beberapa berita yang menyangkut konflik PT. Freeport di Papua dari portal online, kemudian dari data-data dan penjelasan konsep-konsep ini, penulis akan menganalisis pengintegrasian peace journalism dalam konflik PT. Freeport di Papua dan nantinya akan mendapatkan simpulan dari analisis di paper ini.

\section{a. Kajian'Teori}

\section{PemahamanterhadapKonflik}

Dalam istilah dasar, 'konflik'dapat dilihat sebagai bentrokan antara "bermusuhan"dan" menentang" dan adanya elemen, ide atau kekuatan. Definisi awal dijelaskan oleh Coser mendefinisikan konflik sebagai perjuangan atas nilai-nilai dan klaim status, kekuasaan dan sumberdaya. ${ }^{5}$ Definisi lain dari Kries berg menjelaskan konflik sebagai hubungan antara dua atau lebih pihak yang percaya bahwa mereka memiliki tujuan yang berbeda. ${ }^{6}$ Definisi yang lebih modern di berikan oleh Bonta yang mengatakan bahwa konflik merupakan antagonisme interpersonal dan berakhiran dengan adanya pihak yang bermusuhan

\footnotetext{
4Joseph, Teresa. Mediating $W$ ar and Peace: Mass Media and International Conflict.http://iqq.sagepub.com.ezproxy.ugm.ac.id/content/70/3/225.full.pdf + html.diunduhtanggal 16 Juni 2016

${ }^{5}$ Coser, L. The Functions of social conflict. (New York: Free press. 1956)

${ }^{6}$ Kriesberg, L. The sociology of social conflicts. (Englewood Cliffs, NJ: Prentice all. 1973)
} 
antara dua pihak atau lebih. ${ }^{7}$

Sebuah definisi yang lebih luas dijelakan oleh Heidelberg Institute forInternasional Conflict Researchdalam Rukhsana Aslamyang mendefinisikan konflik sebagai: “...Bentrok kepentingan (perbedaan kepentingan pribadi) pada nilai-nilai nasional yang terjadi antara paling sedikit dua pibak (kelompok terorganisir, negara, kelompok negara, organisasi) yang bertekad untukmengejar kepentingan mereka dan memenangkan kasus mereka."8

Dapat di tarik satu benang merah dalam berbagai definisi di atas adalah bahwa konflik memiliki unsur ketidaksepakatan, baik pada poin prinsip, persepsi, nilai-nilai, ideologi atau

budaya. Unsur umum lainnya adalah bahwa konflik adalah proses, terjadi dan berlangsung bertahap. Konflik dengan demikian dapat dilihat dari segi proses dan mengatur hubungan manusia yang memiliki tahap baik dan buruk.

Lynch danGaltungberpendapat; konflikitu ada dengan tujuan untuk kemajuan manusia, suatu kelompok yang berkonflik menghadapinya dengan cara-cara baru, cara-cara yang imajinatif, kreatif, mengubahkonflik sehingga terjadinya peluang untuk meredam konflik tanpa kekerasan. ${ }^{9}$

AnsteydalamMogekwumenjelaskan, istilah konflik sebagai proses. Dia mengatakan bahwa konflik hadir dalam masyarakat baik dalam bentuk 'laten' dan 'manifest'. Konflik ada dalam hubungan ketika pihak percaya bahwa aspirasitidak dapat dicapai secara bersamaan, atau merasakan perbedaan dalam nilai-nilai, keutuhan dan kepentinganmereka(konflik laten) dan sengaja mempekerjakan kekuatan dalam upaya untuk mengalahkan, menetralisir atau menghilangkan satu sama lain untukmelindungi atau memajukan kepentingan mereka dalam interaksi (konflik manifest). ${ }^{10}$

Brahm menarik kurva dari perkembangankonflik, memecahnya menjadi tujuh tahapan konflik yang mencakup tahap laten, tahap munculnya konflik, tahap eskalasi konflik, tahap kebuntuan,tahap penyelesaian sengketa dan perdamaian pasca konflik.Terkait dengan

${ }^{7}$ Bonta, B. Conflict resolution among peace societies: the culture of peacefulness. Journal of Peace Research. 1996

${ }^{8}$ Aslam, Rukhsana. The Role of Media in Conflict: Integrating Peace Journalism in the

Journalism Curriclum.2014.

http://aut.researchgateway.ac.nz/bitstream/handle/10292/7908/AslamR.pdf?se quence $=3$ \&is Allowed $=\mathrm{y}$. diunduhtanggal 16 Juni 2016

'Lynch, J. \& Galtung, J.Reporting Conflict: new directions in peace journalism. (Australia: University of Queensland Press. 2010)

${ }^{10}$ Mogekwu, M.Conflict reporting and peace journalism: in search of a newmodel: lessons from the Nigerian Niger Delta crisis. In I. S. Shaw, J. Lynch, \&R.A. Hackett (Eds.), Expanding peace journalism: comparative and critical approaches. (Sydney: Sydney University Press. 2011) 
konflik adalah konsep terdapat tiga konsep didalamnya yaitu: 'manajemen konflik', 'resolusi konflik' dan 'transformasi konflik'. manajemen konflik mencakup berbagai upaya menuju penanganan konflik positif. ${ }^{11}$ Resolusi konflik menyiratkan bahwa perilaku para pihak yang bertikai tidak memakai kekerasan dan mereka tidak lagi berusuhan. Transformasi konflik adalah istilah yang mengisyaratkan perubahan dalam hubungan antara pihak yang bertentangan selama beberapa periode waktu dan dengan demikian juga mengubah sifat konflik. ${ }^{12}$

Galtungmemperkenalkan konsep peace dan war journalism ${ }^{13}$ pada tahun 1970, menunjukkan hubungan antara manusia dan konflikmelalui segitiga $\mathrm{ABC}$ yang ditunjukkan pada Gambar 1.1:

Gambar. 1

\section{Segitiga ABC konflik Galtung}

$\mathrm{A}$ (Attitude)

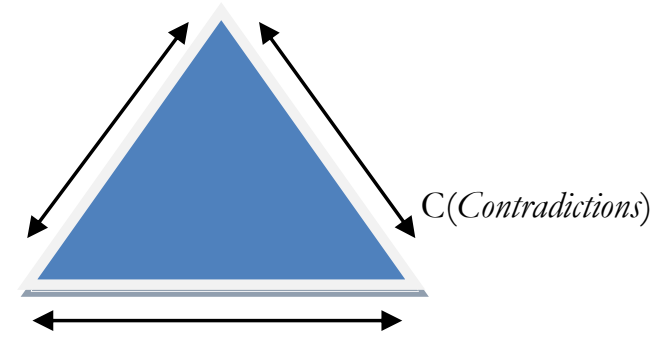

Menurut Galtung, konflik terdiri dari A: asumsi masyarakat dan sikap, B: perilaku dan C: kontradiksi (dalam tindakan). Konflik terjadi ketika ada kontradiksi dalam 'goals' dari sisi yang berbeda dan tidak sesuai dengan pihak lain. Pada 'shock goals', konflik juga dapat menghasilkan kekerasan yang kemudian menjadi sebuah 'permainan' di mana masingmasing sisinya berlawanan satu sama lain. Jadi konflik diibaratkan membentuk segitiga, dan interaksi antara tiga sudut segitiga mencerminkan sifat dinamis dan berkelanjutan dari hubungan manusia. ${ }^{14}$

${ }^{11 B r a h m, ~ E . C o n f l i c t ~ S t a g e s . I n ~ G . ~ B u r g e s s ~ \& ~} H . \quad$ Burgess (Eds).Beyondintractability.http://www.beyondintractability.org/biessay/conflictstages.diunduh 18 Juni 2016

12Lederach, J.P. (2003). Defining Conflict Transformation.Restorative JusticeOnline.http://www.restorativejustice.org/10fulltext/lederach.diunduh 18 Juni 2016

${ }^{13}$ Galtung, J. Peace by peaceful means: Peace and conflict, development and civilization. (London, UK: Sage PublicationsLtd. 1996)

${ }^{14}$ Ibid. 


\section{MaknaPerdamaiandanPeace Jornalism}

Perdamaian selalu dikaitkan dengan perang dan konflik. Barashberpendapatbahwa perdamaian tidak pernah sepenuhnya tercapai, tetapi hanya dapat didekati. ${ }^{15}$ Galtungberpendapat bahwa perdamaian memiliki hubungan yang fatal dengan perang, perdamaian diasumsikan dengan tidak adanya perang atau gencatan senjata. Perdamaian positif adalah kondisi di mana konflik tidak memakai kekerasan atau cara yang dilakukan masyarakat menangani konflik tanpa kekerasan.Perbedaan jurnalisme damai dan jurnalisme perang, terlihat pada karakteristik dari Johan Galtung. ${ }^{16}$

${ }^{15}$ Barash, D.P.Preventing war: building negative peace. In P. Barash (Ed.), Approaches to peace: a reader in peace studies. (Oxford: Oxford University Press. 2000)

${ }^{16}$ Galtung, J. Peace by peaceful means: Peace and conflict, development and civilization. (London, UK: Sage PublicationsLtd. 1996) 
Tabel.1

KarakteristikPeace Journalismdan War Journalism Galtung ${ }^{17}$

\begin{tabular}{|c|c|}
\hline Peace Journalism & W ar Journalism \\
\hline $\begin{array}{l}\text { a. Orientasipada "win-win" } \\
\text { b. Keterbukaanwaktudanruang; } \\
\text { sebabdanhasil, jugahistori/budaya } \\
\text { c. Membuatkonflikmenjaditransparan } \\
\text { d. Memberikansuarakepadasemuapartai/kel } \\
\text { ompokkepentingan; empati, pengertian } \\
\text { e. Melihatkonflik/perangsebagaimasalah, } \\
\text { fokuspadapemciptaankonflik } \\
\text { f. Humanisasi di setiapsisi } \\
\text { g. Proaktif: } \\
\text { pencegahansebelumterjadinyakonflik / } \\
\text { herang } \\
\text { hokuspadaefekkekerasan yang } \\
\text { taknampak (trauma, } \\
\text { i. kerusakanstruktur/budaya) } \\
\text { j. } \text { Fengeksposketidakjujuran di semuasisi } \\
\text { perempuan, anak-anak. }\end{array}$ & $\begin{array}{ll}\text { a. Fokuspada area konflik, } 2 \\
\text { partai, } 1 \text { goal (win) war } \\
\text { b. Zero-sum orientation } \\
\text { c. Ruangdanwaktutertutup; } \\
\text { d. Membuatperangmenjaditi } \\
\text { daktransparan } \\
\text { e. Cenderung propaganda, } \\
\text { menyuarakansatupihak } \\
\text { f. Dehumanisasipada } \\
\text { g. "them" atauliyan/lain } \\
\text { Reaktif: } \\
\text { menunggukekerasansebelu } \\
\text { mmeliput } \\
\text { h. Fokuspadaefek } \\
\text { i. Mengeksposketidakjujura } \\
\text { n } \\
\text { j. Fokuspadapenderitaan } \\
\text { "dirisendiri"/in group } \\
\text { pihakkekerasan yang } \\
\text { tampak } \\
\text { (korbanterluka/terbunuh, } \\
\text { kerusakanmateri) }\end{array}$ \\
\hline
\end{tabular}

Teknik Galtung pada tabel diatas, berorientasi pada perdamaian, berorientasi pada kebenaran, berorientasi pada rakyat dan berorientasi pada solusi.Jika konflik didefinisikan dalam hal hubungan manusia; perdamaian didefinisikan sebagai tidak adanya konflik, tetapi sebagai tidak adanya kekerasan. Terkait dengan konsep "peace", terdapat konsep peacebuilding dan peacekeeping.Peacekeeping didefinisikan sebagai pemeliharaan perdamaian, terutama pencegahan pertempuran antara keduabelah pihak yang berkonflik.Disisi lain, Peacebuildingadalah sebuah konsep komprehensif yang meliputi, menghasilkan dan menopang proses pertempuran konflik. Pendekatan dan tahap yang diperlukan

${ }^{17}$ Galtung, Johan.The Missing On Conflict and Peace And TheMiddle East.2005. https://www.transcend.org/files/article570.html.diunduh 16 Juni 2016 
untuk mengubah konflik ke arah yang lebih baik ${ }^{18}$. Galtung menjelaskan peacebuilding sebagai proses menciptakan struktur mandiri yang menghapus penyebab perang dan menawarkan alternatif dalam perang. Mekanisme tersebut harus dibangun ke dalam struktur masyarakat dan hadir menjadi reservoir untuk sistem itu sendiri untuk dimanfaatkan. ${ }^{19}$

\section{Wacana Media tentangPerdamaian}

Mandelzisberpendapat bahwa dalam kaitannya dengan media, gagasan"Perdamaian" masih belum memadai untuk dikonseptualisasikan. Dalam studinya wacana perdamaian di media berita Israel, ia menemukan bahwa studi pada wacana mediaperdamaian sangat langka dan perdamaian itu sendiri tidak kuat ditekankan di media. ${ }^{20}$ Pengamatan yang dilakukan Groff dan Smokermengatakan bahwa meskipun istilah 'perdamaian' telah semakin populer di kalangan pimpinan UNESCO, tidak ada konsep yang jelas tentang cara menafsirkannya. Mandelzis lebih jauh berpendapat bahwa hal ini terjadi karena kurangnya perspektif tentang 'perdamaian' dan ia juga menjelaskan adanya kelangkaan literatur tentang hubungan antara media massa, komunikasi dan budaya 'perdamaian'. ${ }^{21}$

Bratic dan Schirch, juga berpendapat bahwa sementara telah terjadi pergeseran optimisme dalam peran media dalam konflik, argumen teoritis untuk dampak media terhadap perdamaian kurang dikembangkan. Selain itu, perdebatan menegaskan model tanggung jawab sosial media dan yang universal bersifat filosofis cenderung untuk mengalihkan hal ini karena perdamaian adalah suatu proses, bukan peristiwa. ${ }^{22} \mathrm{Di}$ sisi lain, Tehranianmenjelaskan, media merupakan bagian yang aktif dari konflik. Bagimana media menyajikan pemberitaan terkait konflik tersebut, media memberitakan ada pihak yang menang dan ada

${ }^{18}$ Lederach, J.P. (2003). Defining Conflict Transformation.Restorative Justice Online.http://www.restorativejustice.org/10fulltext/lederach.diunduh 18 Juni $\underline{2016}$

${ }^{19}$ Galtung, J. Peace by peaceful means: Peace and conflict, development and civilization. (London, UK: Sage PublicationsLtd. 1996)

${ }^{20}$ Mandelzis, Lea.Representations of peace in news discourse: Viewpoint and opportunity for peace journalism. In D. Shinar \& W. Kempf (Eds.), Peace journalism: the state of the art. (Germany: Regener. 2007)

${ }^{21}$ Groff, L. \& Smoker, P. (2002).Creating global-local cultures of peace. Global Options.http://www.gmu.edu/academic/pcs/smoker.htm.diunduh 19 Juni 2016

${ }^{22}$ Bratic, V. \& Schirch, L. (2008). The role of media in peace building: Theory and practice. Paper presented at journalistic training in conflict relation situations symposium. http://www.kubatana.net/docs/media/dw journalistsic training symposium 2 008.pdf.diunduh 19 Juni 2016 
pihak yang kalah. Media berupaya untuk 'menjual' pemberitaan konflik tersebut. $^{23}$

\section{Resolusi Konflik dan Transformasi Media}

Bonta mendefinisikan resolusi konflik sebagai proses penyelesaian atau proses penghindaran perselisihan antara individu atau kelompok dengan solusi untuk menahan diri dari tindak kekerasan. ${ }^{24}$ Ini menyiratkan adanya bentuk pihak-pihak yang berusaha untuk meredamkan masalah konflik.Resolusi konflik terdiri dari empat prinsip yaitu; arbitation, litigation, negotiation dan mediation. Sementara dua prinsip pertama memerlukan prosedur formal yang melibatkanproses ruang sidang sedangkan negotiation dan mediation merupakan dua prinsip yang tidak formal, mungkin bisa tidak memerlukan partisipasi pihak ketiga. Biasanya untuk diruang lingkup penelitian, digunakan berinsip negotiation dan mediation. Negosiasi mengacu pada proses tawar-menawar antara keduabelah pihak yang berkonflik, dengan maksud untuk mencapai suatu kesepakatan bersama. ${ }^{25}$ Dalam istilah hukum, negotiation merupakan proses untuk menemukan alternatif penyelesaian atau solusi yang mungkin bisa menengahi konflik.

Mediation adalah proses konsensus di mana pihak yang bersengketa dan pihak perantara antara keduabelah pihak membawa pemahaman yang baik untuk menyelesaikan konflik. ${ }^{26}$ Setelahfakta-fakta dan isu-isu yang menyebabkan konflik diluruskan, maka terjadilah resolusi konflik diantara keduabelah pihak.Mediasi sebagai proses memberikan fleksibilitas kepada pihak-pihak untuk saling bertemu dengan memakai atau tidak memakai pihak ketiga. Tujuan mediasi adalah untuk mepmperbaiki hubungan dan menyelesaikan sengketa, penekanan pada mediasi untuk mencari jalan damai yang masing-masing pihak melupakan kesalahan-kesalahan pada masa lalu sehingga tidak lagi terjadi konflik. ${ }^{27}$ Terkait dengan mediasi ada istilah fasilitasi yang mengacu pada upaya perantara untukmendorong pihak-pihak yang berkonflik untuk bergerak menuju proses negosiasi. Media dapat memunculkan pihak ketiga sebagai bentuk resolusi konflik. Media berfungsi sebagai forum publik, dimana masing-masih pihak yang bersengketa dapat terlibat didalam dialog. Media dapat memainkan peran dalam perdamaian dengan menarik perhatian masyarakat atau politisi untu memfasilitasi

${ }^{23}$ Tehranian, M.Preface. In D. Shinar \& W. Kempf (Eds.), Peace journalism: the state of the art. (Berlin: Regener. 2007)

${ }^{24}$ Bonta, B.Conflict resolution among peace societies: the culture of peacefulness. Journal of Peace Research. 1996.

${ }^{25}$ Ibid.

${ }^{26}$ Spiller, P.Dispute Resolution in New Zealand. (Australia: Oxford University Press. 2002)

${ }^{27}$ Ibid. 
diplomasi atau terlibat dalam perundingan perdamaian. Media dapat memfasilitasi ketika komunikasi antar pihak yang berkonflik terbatas, melalui medialah komunikasi itu dapat tersambung. ${ }^{28}$ berpendapat bahwa konsep konflik laten dan mainfet dapat membantu memahami bagaimana jurnalisme dapat memainkan peran. Media lebih sering memberitakan konflik yang berjenis mainfest. Konflik laten biasanya diabaikan karena sering tidak menarik perhatian audiens. ${ }^{29}$ Konflik mainfest cenderung mengedepankan pelaporan peristiwa yang terjadi akibat konflik, misalnya pelaporan jumlah korban, kerusakan-kerusakan yang terjadi setelah konflik berlangsung, tanda disadari jurnalis telah melakukan pelaporan yang disebut "war journalis".

\section{b. HasildanPembahasan}

\section{Pemberitaan Konflik PT. Freeport di Papua dan Peace Journalism}

Konflik yang terjadi di Papua berakar dari sebuah ketidakadilan yang bersumber dari ketidakmerataan distribusi hasil-hasil pembangunan ekonomi yang dijalankan oleh orde baru. Ketika rezim orde baru berakhir pada pertengahan tahun 1998, konflik ini semakin manifest dan upaya untuk memerdekaan diri juga semakin intensif. Persoalan ini membawa seluruh pemerintahan paska rezim orde baru berupaya keras untuk memikirkan sebuah solusi alternatif bagi penyelesaian konflik yang terjadi di Papua. Dalam hal ini Pemerintah Indonesia mulai menggunakan pendekatanpendekatan yang lebih elegan dan terhormat seperti pendekatan politik dalam konteks domestik dan pendekatan diplomasi atau negosiasi dalam konteks mempengaruhi dunia Internasional dengan maksud agar dunia Internasional tetap mengakui bahwa Papua merupakan bagian integral dariNegara Kesatuan Republik Indonesia.

Pemerintah Indonesia, mengubah status provinsi Papua menjadi daerah otonomi khusus.Pengubahan tersebut ditujukan untuk mengendalikan konflik yang tengah berlangsung di Papua.Usaha serius yang dilakukan oleh pemerintah Indonesiauntuk menangani permasalahan dengan efektif dimulaisejak tahun 1999, dengan penetapan provinsi tersebut sebagai Daerah Otonomi Khusus. ${ }^{30}$

${ }^{28}$ Mogekwu, M. Conflict reporting and peace journalism: in search of a new model: lessons from the Nigerian Niger Delta crisis. In I. S. Shaw, J. Lynch, \&R.A. Hackett (Eds.), (Expanding peace journalism: comparative and critical approaches. Sydney: Sydney University Press. 2011)

${ }^{29}$ Ibid.

${ }^{30}$ Buchanan, Cate (Ed). Pengelolaan Konflik di Indonesia. (Geneva: Centre for Humanitarian Dialoque. 2011) 
Bukan hanya itu saja, konfil-konflik dipapua yang lain misalkan dalam permasalahan kesenjangan ekonomi yaitu hadirnya perusahaan multinasional PT. Freeport McMorran Copper and Gold, kini PT Freeport Indonesia. Akar penyebab konflik ini menurut studi dari Lembaga Ilmu Pengetahuan Indonesia (LIPI) pada tahun 2009adalah marginalisasi orang asli Papua, terutama soal ekonomisebagai efek migrasi, penyebab konflik yang kedua karena kegagalan program pembangunan di Papua untuk mengatasi marginalisasi ekonomi, penyebab ketiga adanya perbedaan pemahaman yang mendasar terhadap sejarah antara Jakarta dan Papua dan yang terakhir warisan kekerasan yang dilakukan negara terhadap masyarakat Papua. $^{31}$

Dari penyebab konflik ini, terlihat jelas adanya marginalisasi ekonomi yang dirasakan orang asli Papua, adanya ketimpangan kesejahteraan antara penduduk dengan karyawan Freeport. Menjelang akhir tahun 2011, tepatnya dalam rentang September-Desember, Papua kembali membara.Setelah terjadinya pemogokan karyawan PT. Freeport Indonesia, rangkaian kekerasan terjadi di tanah Papua.Mulai dari penembakan di Mimika, pemukulan oleh aparat TNI saat diadakannya Kongres Papua III, jika dilihat dari sisi kronologinya, kasus ini memiliki kaitan sebagai dampak dari ekspose yang dilakukan media.

Awalnya pada tanggal 15 September 2011, ribuan pekerja PT. Freeport Indonesia melakukan mogok kerja, yang berakibat aktivitas penambangan lumpuh. Pemogokan tersebut dikarenakan Serikat Pekerja Seluruh Indonesia (SPSI) PT. Freeport Indonesia meminta kenaikan upah dari US $\$ 1,5$ menjadi US\$7,5 per jam. 8 Spontan, lumpuhnya penambangan di PT.Freeport Indonesia mendapat perhatian khusus dari pemerintah.Konflik internal perusahaan ini merambat luas, saat dibenturkan dengan rencana pemerintah untuk merenegosiasi kontrak pertambangan di seluruh Indonesia. ${ }^{32}$

Parahnya, pada 10 Oktober 2011, terjadi bentrok di PT. Freeport dan satu orang tertembak dan konflik pun menjadi tambah luas,saat terjadi penembakan misterius terhadap Margono yang merupakan pamandari politisi senayan, Roy Suryo. Bahkan, penembakan pun terus berlanjut hingga mencuat ke media bahwa ada dugaan uang PT Freeport Indonesia mengalir ke Polri yang akhirnya membawa masyarakat mendesak KPK mengusutinya.

Berikut Penulis petakan penggalan-penggalan pemberitaan media online tentang konflik di Papua yang bersumber dari beberapa portal berita online yaitu: viva.co.id, detik.com dan tribun news. Rentang waktu pemberitaan dari tahun 2009-2011 :

\footnotetext{
${ }^{31}$ Ibid.

${ }^{32}$ Sujito, Arie. Meretas Perdamaian di Tanah Papua. (Yogyakarta: IRE. 
Tabel. 2

Pemberitaan di media online menyangkut Konflik PT Freeport di Papua

\begin{tabular}{|c|c|c|c|}
\hline $\begin{array}{l}\mathbf{N} \\
\mathbf{0}\end{array}$ & $\begin{array}{c}\text { Tanggal/Tahu } \\
\mathbf{n}\end{array}$ & $\begin{array}{l}\text { Nama } \\
\text { Media } \\
\text { Online }\end{array}$ & Judul Berita \\
\hline 1 & 13 Agustus 2009 & Viva.co.id & $\begin{array}{l}\text { "TNI di Balik Konflik Freeport, Itu Fitnah" } \\
\text { http://nasional.news.viva.co.id/news/rea } \\
\text { dit82521-tni-di-balik-konflik-freeport-itu- }\end{array}$ \\
\hline 2 & $\begin{array}{l}8 \text { November } \\
2011\end{array}$ & Viva.co.id & $\begin{array}{l}\text { Konflik Papua Sengaja Dipelihara? } \\
\text { http://www.viva.co.id/ramadan2016/read } \\
\text { L262440-konflik-papua-sengaja-dipelihara }\end{array}$ \\
\hline 3 & 16 Juli 2009 & Detik.com & $\begin{array}{l}\text { Dinilai Jadi Sumber Masalah, Freeport } \\
\text { Diminta Ditutup } \\
\text { http://news.detik.com/berita/1166232/di } \\
\text { nilai-jadi-sumber-masalah-freeport- } \\
\text { diminta-ditutup }\end{array}$ \\
\hline 4 & 20 Januari 2010 & Detik.com & $\begin{array}{l}\text { Aliran Dana PT Freeport Diduga Jadi Salah } \\
\text { Satu Akar Konflik di Papua } \\
\text { http://news.detik.com/berita/1282539/al } \\
\text { iran-dana-pt-freeport-diduga-jadi-salah- } \\
\text { satu-akar-konflik-di-papua }\end{array}$ \\
\hline 5 & $\begin{array}{l}17 \text { Oktober } \\
2011\end{array}$ & Tribun News & $\begin{array}{l}\text { Penembahkan Buruh Freeport Pelanggaran } \\
\text { HAM } \\
\text { http://m.tribunnews.com/nasional/2011/ } \\
\text { 10/17/penembahkan-buruh-freeport- } \\
\text { pelanggaran-ham }\end{array}$ \\
\hline 6 & $\begin{array}{l}1 \text { November } \\
2011\end{array}$ & Tribun News & $\begin{array}{l}\text { Keberadaan Freeport Memang Tak } \\
\text { Diterima Rakyat Papua } \\
\text { http://m.tribunnews.com/nasional/2011/ } \\
\text { 11/01/keberadaan-freeport-memang-tak- } \\
\text { diterima-rakyat-papua?page=2 }\end{array}$ \\
\hline 7 & $\begin{array}{l}25 \text { November } \\
2011\end{array}$ & TribunNews & $\begin{array}{l}\text { Kontras: Ada } 26 \text { Penembakan dan } 16 \\
\text { Korban Tewas di Papua } \\
\text { http://www.tribunnews.com/nasional/20 } \\
\text { 11/11/25/kontras-ada-26-penembakan- } \\
\text { dan-16-korban-tewas-di-papua }\end{array}$ \\
\hline
\end{tabular}




\begin{tabular}{|l|l|l|l|}
\hline 8 & $\begin{array}{l}11 \text { Oktober } \\
2011\end{array}$ & Tribun News & $\begin{array}{l}\text { Karyawan Freeport ke DPR Adukan } \\
\text { Penembakan Aparat } \\
\text { http://m.tribunnews.com/regional/2011/ }\end{array}$ \\
\begin{tabular}{l}
$\frac{10 / 11 / \text { karyawan-freeport-ke-dpr-adukan- }}{\text { penembakan-aparat }}$ \\
\hline
\end{tabular} \\
\hline
\end{tabular}

Sumber: diolah dari viva.co.id, detik.com dan tribun.com

Melalui pendekatan peace jornalism,jurnalisme idealnya harus mampu menjalankan prinsip objektivitas yang memandang jurnalis sebagai pihak yang tidak memihak atau tidak membiaskanrealitas. Penulis ingin melihat bagaimana pemberitaan yang dilakukan media menyangkut peace journalism dalam konflik di Papua ini. Pada judul-judul pemberitaan melalui media online ini, berbagai media online mencoba memberitakan dari sudut-sudut pandang yang berbeda. Viva news edisi 13 Agustus 2009 dengan judul berita "TNI di balik konflik freeport itu fitnah" memberitakan bahwa TNI bukanlah oknum yang menyebabkan terjadinya konflik secara terus menerus, pemberitaan viva news ini mencoba membenarkan kalau anggota TNI lah yang justru membantu. ${ }^{33}$ Disini media memberi pandangan lain terhadap TNI. Pada pemberitaan viva news edisi 8 November 2011 yang berjudul "Konflik Papua Sengaja di Pelihara" dari pembuatan judul jelas terlihat ada suatu dugaan yang ditulis oleh media tentang konflik di Papua memang sengaja dipelihara, pemberitaan dengan judul seperti ini bisa membentuk persepsi pembaca menyangkut penuntasan konflik di Papua memang sengaja di perpanjang oleh pihak kepolisian. ${ }^{34}$ Penulis melihat pemberitaan seperti ini bisa menimbulkan perspektif yang berbeda lagi sehingga memperkeruh suasana.

Pemberitaan dari portal media onlineDetik.com seperti judul berita "Dinilai Jadi SumberMasalah, Freeport Diminta Ditutup" dan "Aliran Dana PT Freeport Diduga Jadi Salah Satu Akar Konflik di Papua" dari judul pemberitaan ini jelas bahwa terlihat pemberitaan menyudutkan satu pihak saja yaitu PT. Freeport, media seolah-olah mendukung pihak yang tidak diuntungkan dalam konflik ini, ada kesenjangan pemberitaan yang terjadi. Walau bagaimanapun idealnya media tidak melulu menyudutkan satu pihak saja karena, bisa akan menyebabkan suasana memanas.

33Viva.co.id."TNI di Balik Konflik Freeport, Itu Fitnab". http://nasional.news.viva.co.id/news/read/82521-tni-di-balik-konflik-freeportitu-fitnah.diunduh 19 Juni 2016
${ }^{34}$ Viva.co.id.
Konflik
Рapua
Sengaja
Dipelihara?.

http://www.viva.co.id/ramadan2016/read/262440-konflik-papua-sengaja-

dipelihara.diunduh 19 Juni 2016 
Pemberitaan dari portal media Tribun news ${ }^{35}$ dengan sangat terangterangan menggunakan judul dengan kata-kata unsur kekerasan dan terdapat banyak korban, contohnya "Penembahkan Burub Freeport Pelanggaran HAM", dalam pemberitaan ini media menganggap bahwa pemerintah tidak bisa melindungi warga negaranya, penembakan buruh PT. Freeport oleh oknum kepolisian dianggap melanggar hak asasi manusia, jelas pemberitaan ini juga menyudutkan pemerintah. Judul lain yaitu "Kontras: Ada 26 Penembakan dan 16 Korban Tewas di Papua" 36 media dengan tegasnya membuat judul berita dengan jumlah korban dari konflik yang terjadi di Papua, pemilihan kata-kata pada judul berita seperti "pembakaran" sepertinya kurang objektif karena pemilihan kata tersebut mengacu pada tindakan pembakaran yang sengaja dilakukan.

Pemberitaan media yang intens terhadap kasus konflik yang ada di Papua bisa dibilangmemberi efek negatif kepada pembacanya. Media dengan perannya sebagai issue intensifier, berpotensi memunculkan isu atau konflik dan mempertajamnya. Bahkan ketika media melakukan blow-up, makapotensi untuk munculnya konflik susulan menjadi semakin besar. Jika dilihat dari perspektif wartawan yang membuat berita. Wartawan mempunyai pekerjaan untuk 'bercerita', maksudnya, wartawan mempunyai tugas untuk menceritakan kembali peristiwa-peristiwa yang terjadi dan akan diinformasikan ke masyarakat, mereka adalah orang-orang yang mealoprakan fakta dengan menggunakan keterampilan mereka yaitu: mengobservasi, mendeskripsikan dan kemudian menuliskan suatu kejadian. Dari pemberitaan-pemberitaan yang ada, pendeskripsian pemberitaan yang dibuat wartawan umumnya hanya menekankan satu pihak saja yang bersalah dalam konflik PT. Freeport ini. Studi tentang peran media dalam konflik yang sedang berlangsung menunjukkan bahwa media jarang melaporkan konflik secara netral.Pemberitaan yang tidak seimbang oleh media, karena media diikuti beberapa faktor yang berkontribusi terhadap pelaporan tersebut. Seperti, tekanan pemerintah, pengaruh politik, mekanisme propaganda, pertimbangan komersial, budaya poltiki, norma dan tradisi masyarakat dan emosi nasionalisme. Dibawah pengaruh faktor-faktor ini, frame media dalam melaporkan konflik selalu ada kepentingan-kepentingannya sendiri. Seperti pada konflik ini, frame media cenderung hanya menyudutkan satu pihak saja. Lalu bagaimana peran media sebagai agen perdamaian dalam situasi konflik? Sebelum membahasnya lebih dalam, penulis berpendapat bahwa hal ini kembali lagi bagaimana media memberi framing dan agenda setting pada pemberitaan konflik tersebut. Jika agendanya tidak menonjolkan kekerasan

${ }^{35}$ Tribun News.Penembabkan Burub Freeport Pelanggaran HAM. http://m.tribunnews.com/nasional/2011/10/17/penembahkan-buruh-freeportpelanggaran-ham.diunduh 19 Juni 2016

36Tribun News.Kontras: Ada 26 Penembakan dan 16 Korban Tewas di Papua. http://m.tribunnews.com/nasional/2011/11/01/keberadaan-freeport-memangtak-diterima-rakyat-papua?page $=2$. diunduhpada 19 Juni 2016 
(non-violances) dan framingnya adalah perdamaian (peaces) hal ini menjadikan media mempunyai orientasi untuk mengurangi konflik dan mendukung pemulihan hubungan serta dapat mempengaruhi opini publik terhadap penyelesaian konflik. ${ }^{37}$ Tapi apa yang terjadi pada pemberitaan konflik di Papua ini sepertinya sangat jauh dari apa yang dikatakan Lynch dan Galtung, penonjolah kekerasan justru yang paling sering diberitakan, pemilihan headline-headline yang "panas" kerap dilakukan oleh media, framing yang disuguhkan pun jauh dari istilah perdamaian (peace) malah lebih berorientasi pada peperangan (war).

Jika melihatnya dari karakteristik pemberitaan yang damai dalam pemikiran Galtung, sepertinya pemberitaan di mediaonlineIndonesia khususnya dalam konflik di Papua ini belum memenuhi kriteria pemberitaan yang damai. Karakteristikpeace journalism galtung menjelaskan bahwa pemberitaan berorientasi pada win-win solution tak ada yang menang dan kalah itu artinya pemberitaan seharusnya tidak menyudutkan satu pihak saja, bagaimanapun pihak yang disudutkan bersalah pasti juga mempunyai alasan, pemberitaan yang ada tidak menjelaskan historis terjadinya konflik tersebut, media lebih menyoroti pemberitaan terhadap korban penembakan, penudingan diberbagai pihak dan kerugian-kerugian yang dialami oleh pihak yang merasa tertindas. Media sangat jarang memberitakan pihak manajemen PT. Freeport untuk bersuara, sehingga framing yang terbentuk hanya sebatas pihak-pihak yang menjadi korban karena konflik ini. Media lebih berfokus pada pemberitaan kekerasan yang 'nampak' seperti korban penembakan dan lain sebagainya, media juga tidak mengenengahkan pemberitaan konflik antara kedua belah pihak.

Terkait dengan konsep peace jornalism, media nampaknya kurang membuat pemberitaan konflik yang berorientasi kepada perdamaian/memelihara perdamaian yang dinamakan peacekeeping, media hanya menikmati pemberitaan yang bersifat konflik "mainfest" konflik yang besar sehingga menarik perhatian pembaca seperti ada istilah yang sering didengar yaitu "bad news is a god news", harusnya media bisa membawa pemberitaan ini ke arah yang lebih baik seperti prinsip dari konsep peace itu sendiri yaitu "peacebuilding" media harus menciptakan struktur mandiri yang pemberitaan nya mengarah kepada orientasi perdamaian perang.

Media yang membawa prinsip resolusi konflik mungkin jarang sekali ditemukan, media seharusnya menjadi pihak yang meredam masalah konflik, misalnya pada konflik PT. Freeport di Papua ini. Jika media memposisikan dirinya sebagai mediation, media bisa memunculkan atau menawarkan solusisolusi untuk pihak yang berkonflik namun hal ini nampaknya cukup sulit dilakukan. Yang memicu adanya resolusi konflik ini pada intinya, media memberitakan fakta-fakta dan isu-isu yang menyebabkan koflik diantara

${ }^{37}$ Lynch, J. \& Galtung, J.Reporting Conflict: new directions in peace journalism.(Australia: University of Queensland Press. 2010) 
keduabelah pihak.Media dapat memunculkan pihak ketiga sebagai bentuk resolusi konflik. Media berfungsi sebagai forum public, media dapat memainkan peran dalam perdamaian dengan menarik perhatian masyarakat atau politisi untuk memfasilitasi diplomasi atau terlibat dalam perundingan perdamaian.Nampaknya bentuk-bentuk peran media yang seperti ini belum ditemukan dari beberapa pemberitaan yang penulis kutip. Agaknya wartawan/media lebih menyukai pemberitaan konflik yang "mainfest", karena apabila media menerapkan pemberitaan konflik yang "laten", biasanya sering tidak menarik perhartian pembaca. Konflik mainfest yang diberitakan media cenderung mengedepankan pelaporan peristiwa yang terjadi akibat konflik, misalnya pelaporan jumlah korban, kerusakankerusakan yang terjadi setelah konflik berlangsung, seperti pada pemberitaan konflik PT. Freeport di Papua ini, tanpa disadari atau tidak media dan wartawannya telah melakukan pelaporan yang disebut "war journalis".

Lalu apakah benar peace journalism dalam pemberitaan ini sulit untuk ditemukan dan dilakukan? Memang benar, jika berbicara mengenai 'perdamaian' seperti yang dikatakan Mandelzis ${ }^{38}$ dalam studinya, perdamaian itu sendiri tidak kuat ditekankan pada wacana media, nampaknya media tidak bisa terbebas dari penyajian pemberitaan konflik yang selalu melibatkan ada pihak yang 'menang' dan pihak yang 'kalah' karena, pada dasarnya ideologi materialisasi media sangat kental, media berupaya untuk "menjual" pemberitaan konflik tersebut.

\section{Penutup}

Dari analisis yang telah dilakukan penulis, dapat ditarik kesimpulan pemberitaan dibeberapa media online, media belum dapat mewujudkan peace journlism atau membuat pemberitaan konflik yang damai. Dari berbagai sumber berita yang penulis rangkum melalui media online, pemberitaan yang menyangkut konflik PT. Freeport di Papua media cenderung membawa perannya sebagaiissue intensifier yang pemberitaannya berpotensimemunculkanisuataukonflikdanmempertajamnya.Dari pemberitaanpemberitaan yang ada, pendeskripsian pemberitaan yang dibuat wartawan umumnya hanya menekankan satu pihak saja yang bersalah, media tidak melaporkan konflik secara netral. Hal ini tidak terlepas dari media diikutibeberapafaktor yang berkontribusiterhadappelaporantersebut. Untuk mewujudkan peace journalism, media harus menetapkan frame dan agenta setting yang akan di buat dalam pemberitaan. Jikaagendanyatidakmenonjolkankekerasan (non-violances) danframingnyaadalahperdamaian (peaces) halinimenjadikan media mempunyaiorientasiuntukmewujudkan peace jornalism, namun pada

${ }^{38}$ Mandelzis, Lea. Representations of peace in news discourse: Viewpoint and opportunity for peace journalism. In D. Shinar \& W. Kempf (Eds.), Peace journalism: the state of the art. (Germany: Regener. 2007) 
pemberitaaan konflik PT. Freeport ini media lebih menonjolkan pemberitaan kekerasan, seperti headline-headline berita yang "panas" kerap dibuat oleh media, dan framing yang disuguhkan pun jauh dari istilah perdamaian (peace) media malah lebih berorientasi pada peperangan (war), ini mengindikasikan bahwa peace journalism belumlah hidup dalam pemberitaan konflik. 


\section{Daftar Pustaka}

Barash, D.P. (2000). Preventing war: building negative peace. In P. Barash (Ed.), Approaches to peace: a reader in peace studies. Oxford: Oxford University Press.

Bonta, B. (1996). Conflict resolution among peace societies: the culture of peacefulness. Journal of Peace Research.

Buchanan, Cate (Ed). (2011). Pengelolaan Konflik di Indonesia. Geneva: Centre for Humanitarian Dialoque.

Coser, L. (1956). The Functions of social conflict. New York: Free press.

Galtung, J. (1996). Peace by peaceful means: Peace and conflict, development and civilization. London, UK: Sage PublicationsLtd.

Kriesberg, L. (1973). The sociology of social conflicts. Englewood Cliffs, NJ: Prentice Hall.

Lynch, J. \& Galtung, J. (2010). Reporting Conflict: new directions in peace journalism. Australia: University of Queensland Press.

Mandelzis, Lea. (2007). Representations of peace in news discourse: Viewpoint and opportunity for peace journalism. In D. Shinar \& W. Kempf (Eds.), Peace journalism: the state of the art. Germany: Regener.

Mogekwu, M. (2011). Conflict reporting and peace journalism: in search of a new model: lessons from the Nigerian Niger Delta crisis. In I. S. Shaw, J. Lynch, \&R.A. Hackett (Eds.), Expanding peace journalism: comparative and critical approaches. Sydney: Sydney University Press.

Spiller, P. (2002). Dispute Resolution in New Zealand. Australia: Oxford University Press.

Sujito, Arie. (2009). Meretas Perdamaian di Tanah Papua. Yogyakarta: IRE.

Tehranian, M. (2007).Preface. In D. Shinar \& W. Kempf (Eds.), Peace journalism: the state of the art. Berlin: Regener.

\section{Jorunal Online}

Aslam, Rukhsana. (2014). The Role of Media in Conflict: Integrating Peace Journalism in the Journalism

Curriclum.http://aut.researchgateway.ac.nz/bitstream/handle/10292/7908/Asla $\underline{m R}$.pdf? sequence $=3 \&$ is Allowed $=\mathrm{y}$.

Brahm, E. (2003). Conflict Stages.In G. Burgess \& H. Burgess (Eds).Beyond intractability.http://www.beyondintractability.org/bi-essay/conflictstages. 
Bratic, V. \&Schirch, L. (2008). The role of media in peace building: Theory and practice. Paper presented at journalistic training in conflict relation situations symposium. http://www.kubatana.net/docs/media/dw journalistsic training symp osium 2008.pdf.

Galtung, Johan. (2005). The Missing On Conflict and Peace AndTheMiddle East. https://www.transcend.org/files/article570.html.

Groff, L. \& Smoker, P. (2002).Creating global-local cultures of peace.GlobalOptions.http://www.gmu.edu/academic/pcs/smoker.htm.

Joseph, Teresa. 2014.Mediating W ar and Peace: Mass Media and International Conflict. http://iqq.sagepub.com.ezproxy.ugm.ac.id/content/70/3/225.full.pdf+ html.

Lederach, J.P. (2003). Defining Conflict Transformation.Restorative Justice Online.http://www.restorativejustice.org/10fulltext/lederach. Diunggah

Lynch, Jake \& Annabel McGoldrick. 2012. Responses to Peace Journalism. http://jou.sagepub.com.ezproxy.ugm.ac.id/content/14/8/1041.full.pdf+ $\underline{\mathrm{html}}$.

PUTRA, Robby Aditya. Dampak Film Para Pencari Tuhan Jilid X Terhadap Religiusitas Remaja. Jurnal Dakwah dan Komunikasi, [S.I.], v. 3, n. 1, p. 1-24, july 2018. ISSN 2548-3366

\section{Berita Online:}

Viva.co.id. (2009). "TNI di Balik Konflik Freeport, Itu Fitnab" http://nasional.news.viva.co.id/news/read/82521-tni-di-balik-konflikfreeport-itu-fitnah.

Viva.co.id. (2011). Konflik Papua Sengaja Dipelihara?

http://www.viva.co.id/ramadan2016/read/262440-konflik-papuasengaja-dipelihara.

detik.com. (2009). Dinilai Jadi Sumber Masalah, Freeport Diminta Ditutup http://news.detik.com/berita/1166232/dinilai-jadi-sumber-masalahfreeport-diminta-ditutup.

detik.com. (2010). Aliran Dana PT Freeport Diduga Jadi Salab Satu Akar Konflik di Papua

http://news.detik.com/berita/1282539/aliran-dana-pt-freeport-didugajadi-salah-satu-akar-konflik-di-papua.

Tribun News. (2011). Penembabkan Burub Freeport Pelanggaran HAM http://m.tribunnews.com/nasional/2011/10/17/penembahkan-buruhfreeport-pelanggaran-ham.

Tribun news. (2011). Keberadaan Freeport Memang Tak Diterima Rakyat Papua 
http://m.tribunnews.com/nasional/2011/11/01/keberadaan-freeportmemang-tak-diterima-rakyat-papua?page $=2$.

Tribun News. (2011). Kontras: Ada 26 Penembakan dan 16 Korban Tewas di Papua http://m.tribunnews.com/nasional/2011/11/01/keberadaan-freeportmemang-tak-diterima-rakyat-papua?page $=2$.

Tribun News. (2011). Karyawan Freeport ke DPR Adukan Penembakan Aparat http://m.tribunnews.com/regional/2011/10/11/karyawan-freeport-kedpr-adukan-penembakan-aparat. Diakses 20 Juni 2016 